\title{
Determination of radial quantum dot position in trumpet nanowires from far field measurements
}

Østerkryger, Andreas Dyhl; Gregersen, Niels; Fons, Romain; Stepanov, Petr; Jakubczyk, Tomasz; Bleuse, Jöel; Gérard, Jean-Michel; Claudon, Julien

Publication date:

2017

Document Version

Publisher's PDF, also known as Version of record

Link back to DTU Orbit

Citation $(A P A)$ :

Østerkryger, A. D., Gregersen, N., Fons, R., Stepanov, P., Jakubczyk, T., Bleuse, J., Gérard, J-M., \& Claudon, J. (2017). Determination of radial quantum dot position in trumpet nanowires from far field measurements. Poster session presented at 17th International Conference on Numerical Simulation of Optoelectronic Devices, Lyngby, Denmark.

\section{General rights}

Copyright and moral rights for the publications made accessible in the public portal are retained by the authors and/or other copyright owners and it is a condition of accessing publications that users recognise and abide by the legal requirements associated with these rights.

- Users may download and print one copy of any publication from the public portal for the purpose of private study or research.

- You may not further distribute the material or use it for any profit-making activity or commercial gain

- You may freely distribute the URL identifying the publication in the public portal 


\section{Determination of radial quantum dot position in needle nanowires from far-field measurements}

Andreas Dyhl Osterkryger* and Niels Gregersen

DTU Fotonik, Department of Photonics Engineering, Technical University of Denmark, Ørsteds Plads, DK-2800 Kongens Lyngby *presenting author, E-mail: adyh@fotonik.dtu.dk

Romain Fons, Petr Stepanov, Tomasz Jakubczyk, Jöel Bleuse, Jean-Michel Gérard and Julien Claudon

Univ. Grenoble Alpes, INAC-PHELIQS and CEA, INAC-PHELIQS, ”Nanophysique et semiconducteurs” group, F-38000 Grenoble, France

\section{Tapers for single-photon sources}

- Quantum dots embedded in tapered nanowires have been shown as good candidates for realising an efficient single-photon source [1,2].

- For optimal efficiency the quantum dot should be placed on-axis. In this work we want to develop, a method for determining the quantum dot position in the nanowire based on the far-field emission pattern. The modelling is done using an open-geometry Fourier modal method [3], and a near-field to far-field transformation [4].

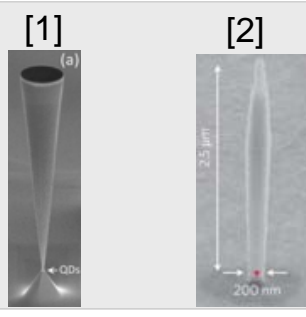

II. Modes and spontaneous emission rates in a nanowire

- The coupling of the quantum dot to the optical modes depends on the radial position of the quantum dot.

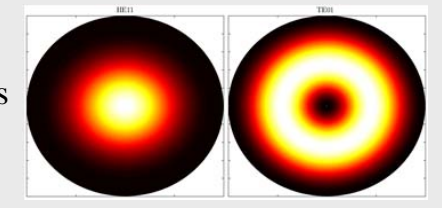

Figure 1: Mode profiles for the HE11 and TE01 modes.

- Interference between the HE11 and TE01 modes leads to different power distributions in the NW, that should be visible in the far-field.

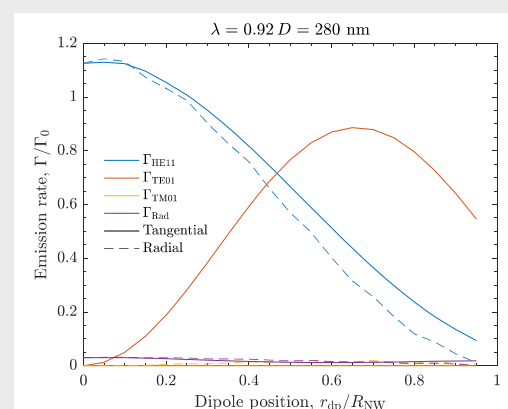

Figure 2: Spontaneous emission rate for a dipole in a nanowire.

III. oFMM and near-field to far-field transformation

- Field is expanded on eigenmodes:

$$
E(r, \phi, z)=\sum_{n, j} a_{n j}(r) E_{n j}(r) \exp (\mathrm{i} n \phi) \exp \left(\mathrm{i} \beta_{j}\right)
$$

- Eigenmodes are expanded as a Fourier integral - open BCs:

$$
E_{r, n j}=\mathrm{i} \int\left[b_{n j}^{E}(k) J_{n+1}(k r)-c_{n j}^{E}(k) J_{n-1}(k)\right] k \mathrm{~d} k
$$

- Far-field is computed as:

where,

$$
E_{\theta, n j, \mathrm{far}} \cong-\frac{\mathrm{i} k_{0} \exp \left(-\mathrm{i} k_{0} r\right)}{4 \pi r}\left(L_{\phi, n j}+\eta N_{\theta . n j}\right)
$$

$$
\begin{gathered}
N_{\theta, n j}=4(-\mathrm{i})^{n} \pi \cos \theta \cos n \phi \sum_{m} \Delta k_{m}\left(b_{m j n}^{H}-c_{m j n}^{H}\right) \delta\left(k_{m}-k_{0} \sin \theta\right) \\
L_{\phi, n j}=4(-\mathrm{i})^{n-1} \pi \cos n \phi \sum_{m} \Delta k_{m}\left(b_{m j n}^{E}+c_{m j n}^{E}\right) \delta\left(k_{m}-k_{0} \sin \theta\right)
\end{gathered}
$$

IV. Far-fields for needle structure

- Measured far-fields for needle with $D_{\text {Bot }}=182 \mathrm{~nm}$ (to be confirmed) and NA $=0.75$.

- Simulated far-fields with $D_{\text {Bot }}=200 \mathrm{~nm}$, have good agreement with measurements.

- Cut-off for TE01 mode is at $d / \lambda=0.23$, interference is still present - how?

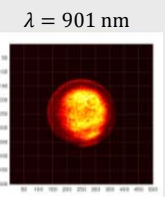
$D / \lambda=0.202$ Figure 3: Meas
quantum dots.

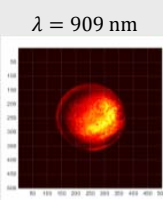

$D / \lambda=0.200$

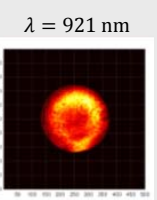

$D / \lambda=0.197$

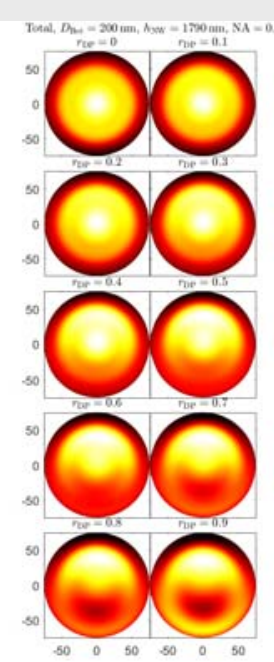

Figure 4: Simulated far-fields, where $D / \lambda=0.22$

V. Radiation mode or guided mode?

- The guided modes exist as radiation modes just before they are guided.

Guided modes: $k_{0}^{2} \leq \beta^{2}<\left(n k_{0}\right)^{2}$ Radiation modes: $0 \leq \beta^{2}<k_{0}^{2}$ Evanescent modes: $\beta^{2}<0$

- These semi-guided radiation modes will interfere with the guided HE11 mode, and only slowly escape the nanowire.

- A simple 2-mode model is therefore not enough.

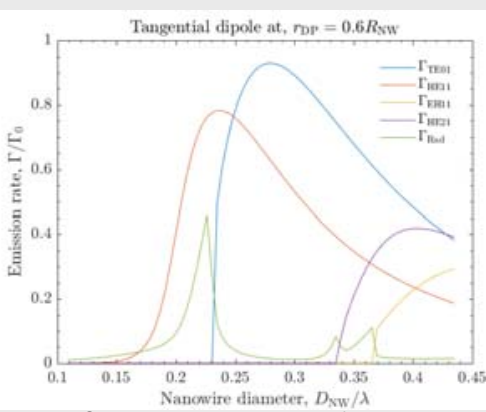

Figure 5: Spontaneous emission rate for a dipole in a Nanowire placed $0.6 R_{\mathrm{NW}}$ off axis.

[1] Stepanov, P. et al., "Highly directive and Gaussian far-field emission from “giant” photonic trumpets,” Appl. Phys. Lett. 107, 141106 (2015)
[2] J. Claudon, J. Bleuse, N. S. Malik, M. Bazin, P. Jaffrennou, N. Gregersen, C. Sauvan, P. Lalanne, and J.-M. Gérard, “A highly efficient single-photon source based on a quantum dot in a photonic nanowire”, Nature Photonics 4 (2010) [3] T. Häyrynen, J. R. de Lasson, and N. Gregersen, “Open-geometry Fourier modal method: modeling nanophotonic structures in infinite domains”, J. Opt. Soc. Am. A 33, 1298 (2016).

[4] C. A. Balanis, Advanced Engineering Electromagnetics (Wiley, 1989), vol. 1, chap. 6 